\title{
Comparison of anticoagulated versus non- anticoagulated patients with intra-aortic balloon pumps
}

\author{
Julie Kelly ${ }^{*}$ (D, Rhynn Malloy and Danielle Knowles
}

\begin{abstract}
Background: There is limited guidance regarding the use of anticoagulation in patients on intra-aortic balloon pumps (IABP). The purpose of this study is to compare the safety outcomes in anticoagulated versus nonanticoagulated patients with an IABP.

Methods: This was a single center, retrospective chart review of patients admitted to the coronary care unit or cardiac surgery unit who received an IABP from May 2015 to July 2018. Patients who were anticoagulated with heparin while on an IABP were compared to those who were not anticoagulated. Major endpoints included a composite of thrombotic events and a composite of bleeding events. The major composite endpoint of thrombotic events included the incidence of ischemic stroke, any venous thromboembolism, device thrombosis, and limb ischemia. The major composite endpoint of bleeding events included major access site bleeding, minor access site bleeding, major non-access site bleeding, and minor non-access site bleeding. Minor endpoints included any major endpoint events occurring within 24 and $48 \mathrm{~h}$ of IABP insertion, hospital length of stay, intensive care unit length of stay, and in-hospital mortality.
\end{abstract}

Results: A total of 185 patients were evaluated for inclusion and 147 were included in the final analysis. There were 82 and 65 patients in the heparin and non-heparin groups, respectively. The composite endpoint of thrombotic events occurred in 7.3 and $7.7 \%$ in the heparin and non-heparin groups, respectively $(p=1)$. The composite bleeding endpoint occurred in 20.7 and $20.0 \%$ in the heparin and non-heparin groups, respectively $(p=0.91)$. There were no differences found in minor endpoints between groups.

Conclusion: There were no significant differences found in major endpoints of bleeding and thrombotic events in patients who received anticoagulation while on an IABP versus those who did not receive anticoagulation.

Keywords: Intra-aortic balloon pumps, Anticoagulation, Mechanical circulatory support

\footnotetext{
* Correspondence: Jkelly30@bwh.harvard.edu

Presented in part at 2019 American College of Cardiology Meeting (New Orleans, LA) and the Massachusetts Society of Health System Pharmacist Meeting (Lowell, MA).

Department of Pharmacy Services, Brigham and Women's Hospital, 75 Francis St Boston, Boston, MA 02215, USA
}

(c) The Author(s). 2021 Open Access This article is licensed under a Creative Commons Attribution 4.0 International License, which permits use, sharing, adaptation, distribution and reproduction in any medium or format, as long as you give appropriate credit to the original author(s) and the source, provide a link to the Creative Commons licence, and indicate if changes were made. The images or other third party material in this article are included in the article's Creative Commons licence, unless indicated otherwise in a credit line to the material. If material is not included in the article's Creative Commons licence and your intended use is not permitted by statutory regulation or exceeds the permitted use, you will need to obtain permission directly from the copyright holder. To view a copy of this licence, visit http://creativecommons.org/licenses/by/4.0/. The Creative Commons Public Domain Dedication waiver (http://creativecommons.org/publicdomain/zero/1.0/) applies to the data made available in this article, unless otherwise stated in a credit line to the data. 


\section{Introduction}

Intra-aortic balloon pumps (IABPs) are a form of mechanical circulatory support used to enhance cardiac output and increase coronary artery perfusion. Heparin is often used in patients with an IABP, as early registry data have shown an increased risk of limb ischemia and other thrombotic events [1]. Due to the risk of platelet shearing and platelet adhesion to the IABP membrane, thrombocytopenia is a common complication that leads to an increased risk of bleeding [1-3]. The bleeding and thrombotic risks of IABP placement in addition to the limited definitive data make it difficult to determine an optimal anticoagulation strategy. Current mechanical circulatory support guidelines make a brief, general statement that each institution should establish their own protocol on anticoagulation in IABPs based on patient specific risk factors [4].

There is a lack of data available to provide guidance on whether patients with an IABP should be anticoagulated. One animal trial randomized 25 pigs to either systemic heparin, heparin-bound IABP, or no heparin. The IABPs were examined for thrombus, and there was no evidence of thrombus in either heparin group, however there was statistically more device thrombosis found in the non-heparin group [5]. In addition to animal studies, a small randomized trial and a cohort study evaluated the use of anticoagulation in patients with an IABP with variable patient populations and inconsistent results $[6,7]$.

Brigham and Women's Hospital uses IABPs across multiple services, including the coronary care unit (CCU) and the cardiac surgery unit (CSICU). In the $\mathrm{CCU}$, it is common practice to anticoagulate patients on an IABP, typically using heparin with a partial thromboplastin time (PTT) goal of $60-80 \mathrm{~s}$. The CSICU does not typically utilize anticoagulation by either infusion or bolus unless they are on an assist ratio of $1: 2$ to 1 : 3 for greater than $30 \mathrm{~min}$. Our institution utilizes non-heparin coated Datascope $\odot$ manufactured IABPs size 30 to $50 \mathrm{~cm}$. CSICU patients typically have IABPs placed in the operating room (OR). IABP placement in CCU patients typically occurs in the catheterization lab, however this can vary based on clinic scenario. The purpose of this study was to provide further insight into the need for anticoagulation in IABPs by comparing bleeding and thrombotic outcomes in a non-anticoagulated versus anticoagulated population of patients with an IABP.

\section{Methods}

This was a single center, retrospective study at a tertiary academic medical center, approved by the Partner's Healthcare Institutional Review Board. All data were obtained from electronic medical records.
Patients were included if they were admitted to the CCU or CSICU from June 2015 to July 2018 with an IABP placed at any time during the admission. Patients were excluded if they were placed on if they were on an anticoagulant other than unfractionated heparin while on an IABP, or if they received an IABP after an endarterectomy procedure. Patients who received therapeutic unfractionated heparin (UFH) were compared to those who did not receive anticoagulation. Additionally, a subgroup analysis was performed excluding patients who were on anticoagulation at home prior to hospitalization. This was done to specifically examine patients who did not have another indication for anticoagulation other than the IABP device.

The major safety endpoint included a composite of major and minor non-access site bleeding, and major and minor access site bleeding, both defined by the International Society on Thrombosis and Haemostasis (ISTH) [8]. The major endpoint of thrombotic events included a composite of incidence of ischemic stroke, any venous thromboembolism, device thrombosis, and limb ischemia. Bleeding and thrombotic events were collected from the time of IABP insertion until the end of the indexed hospitalization. Minor endpoints included major endpoint events occurring within 24 and $48 \mathrm{~h}$ of IABP insertion, hospital length of stay, intensive care unit length of stay, and in-hospital mortality. Time on heparin, PTT goal, and time in goal PTT range were collected for the heparin group in addition to the concomitant use of aspirin and dual antiplatelet therapy (DAPT) with aspirin and a $\mathrm{P}_{12} \mathrm{Y}_{12}$ inhibiter.

Continuous data were compared using t-test for parametric data and Mann Whitney U statistical testing for non-parametric data as appropriate. Categorical data were compared using Chi-Square test and Fisher's Exact test as appropriate. Statistical significance was set at a level of $p<0.05$. In addition, a post-hoc analysis compared major and minor outcomes between the two groups using a logistic regression multivariate analysis adjusted for sex, creatinine clearance, use of DAPT, and patient's location (CCU versus CSICU). Statistical analyses were performed using SPSS and STATA software.

\section{Results}

Of the 185 patient charts that were evaluated for inclusion, 147 patients were included in the final analysis. A total of 82 patients were included in the heparin group and 65 patients in the non-heparin group (see Fig. 1).

Patient baseline characteristics were similar between the two groups with the exception of a lower incidence of baseline valvular disease which was lower in the heparin group as compared to the non-heparin group (15.9\% vs $36.9 \%)$ (Table 1$)$. The majority of heparinized patients were admitted to the CCU (58.5\%) while the 


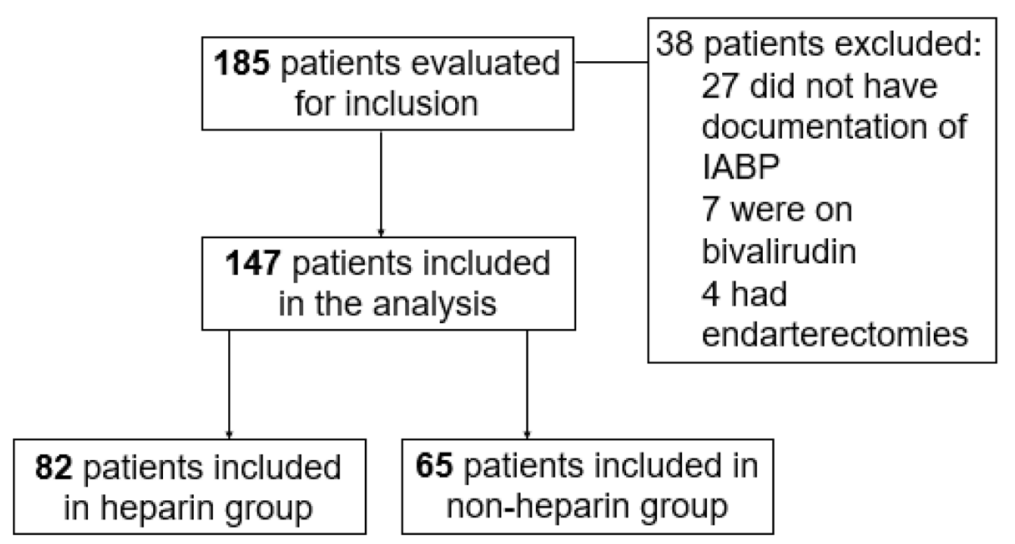

Fig. 1 Patient Enrollment. ECMO = extracorpeal membrane oxygenation

majority of non-heparinized patients were admitted to the CSICU (83.1\%).

The heparin group had more patients with a primary diagnosis of ST-elevation myocardial infarction (STEMI) as compared to the non-heparin group ( $22 \%$ vs $4.6 \%$, $p<0.01$ ), while there were fewer patients with a primary diagnosis of coronary artery bypass graft (CABG) as compared to the non-heparin group ( $14.6 \%$ vs $56.9 \%$, $p<0.01$ ) (Table 2). Patients in the heparin group had a higher median time on an IABP as compared to the non-heparin group (42 h; [IQR, 30-68] vs $26 \mathrm{~h}$; [IQR, 17-45], $p<0.01$ ) with a longer median time in the $1: 1$ assist ratio setting as compared to the non-heparin group ( $36 \mathrm{~h}$; [IQR, 18.8-62.5] vs $19 \mathrm{~h}$; [IQR, 10-40], $p<$ 0.01 ). Time in the $1: 2$ and $1: 3$ assist ratios was similar between the two groups. The majority of patients in the

Table 1 Baseline Characteristics

\begin{tabular}{|c|c|c|}
\hline & $\begin{array}{l}\text { Heparin group } \\
(n=82)\end{array}$ & $\begin{array}{l}\text { Non-heparin } \\
\text { group }(n=65)\end{array}$ \\
\hline Age (years) $)^{a}$ & $67 \pm 10.8$ & $68 \pm 12.1$ \\
\hline Sex (male) & $52(63.4)$ & $51(78.5)$ \\
\hline Body mass index $\left(\mathrm{kg} / \mathrm{m}^{2}\right)^{a}$ & $29.3 \pm 6.3$ & $29.2 \pm 7.5$ \\
\hline Creatinine clearance $(\mathrm{mL} / \mathrm{min})^{a}$ & $67.2 \pm 31.3$ & $62.7 \pm 34.5$ \\
\hline Admitted to coronary care unit & $48(58.5)$ & $11(16.9)$ \\
\hline Admitted to cardiac surgery & $34(41.5)$ & $53(83.1)$ \\
\hline Hypertension & $58(70.7)$ & $55(84.6)$ \\
\hline Atrial arrhythmias & $18(22.0)$ & $14(21.5)$ \\
\hline Ventricular arrhythmias & $10(12.2)$ & $8(12.3)$ \\
\hline Valvular disease & $13(15.9)$ & $24(36.9)$ \\
\hline Coronary artery disease & $47(72.3)$ & $39(60.0)$ \\
\hline Heart failure & $25(30.5)$ & $21(32.3)$ \\
\hline $\begin{array}{l}\text { On concurrent extracorpeal } \\
\text { membrane oxygenation }\end{array}$ & $10(12.2)$ & $1(1.5)$ \\
\hline
\end{tabular}

All values are $\mathrm{n}(\%)$ unless otherwise specified ${ }^{a}$ mean \pm standard deviation heparin group had a documented goal PTT of 60-80 s $(65.9 \%)$ and patients were in goal range $44.8 \%$ of the time on average (Table 3). There was no difference in the concomitant use of aspirin monotherapy between the heparin group and non-heparin group (Table 3). There were more patients in the heparin group on DAPT $(26.8 \%$ vs $13.8 \%, p<0.03)$.

The bleeding endpoint occurred in 17 (20.7\%) heparin patients as compared to 13 (20.0\%) non-heparin patients $(p=0.91)$ (Table 4). Of the patients in the heparin group who had a bleeding event, 9 patients had a PTT goal of $60-80 \mathrm{~s}, 3$ had a PTT goal of $50-70 \mathrm{~s}, 3$ patients had a PTT goal of 40-60, and 2 patients had a PTT goal of 50-60. There were no statistically significant differences in each individual component of the composite bleeding endpoint. The thrombotic endpoint occurred in $6(7.3 \%)$ of patients in the heparin group as compared to $5(7.7 \%)$ of patients in the non-heparin group $(p=0.1)$. There was no statistically significant difference in any of the individual components of this endpoint, including limb ischemia, device thrombosis, venous thromboembolism, or ischemic stroke. When the post-hoc logistic

Table 2 Primary Diagnosis

\begin{tabular}{lll}
\hline & $\begin{array}{l}\text { Heparin group } \\
(\boldsymbol{n}=\mathbf{8 2})\end{array}$ & $\begin{array}{l}\text { Non-heparin group } \\
(\boldsymbol{n}=\mathbf{6 5})\end{array}$ \\
\hline STEMI & $18(22.0)$ & $3(4.6)$ \\
NSTEMI & $11(13.4)$ & $3(4.6)$ \\
Cardiogenic shock & $16(19.5)$ & $9(13.8)$ \\
CABG & $12(14.6)$ & $37(56.9)$ \\
Valve replacement & $7(8.4)$ & $11(16.9)$ \\
Tachyarrhythmias & $9(11.0)$ & $0(0)$ \\
Other & $9(11.0)$ & $2(3.1)$ \\
\hline
\end{tabular}

All values are $n(\%)$

STEMI ST elevated myocardial infarction, NSTEMI non-ST elevated myocardial infarction, $C A B G$ coronary artery bypass graft 
Table 3 Intra-Aortic Balloon Pump and Antithrombotic Characteristics

\begin{tabular}{|c|c|c|}
\hline & $\begin{array}{l}\text { Heparin group } \\
(n=82)\end{array}$ & $\begin{array}{l}\text { Non-heparin } \\
\text { group }(n=65)\end{array}$ \\
\hline Time on IABP (hours) ${ }^{a}$ & $42(30-68)$ & $26(17-45)$ \\
\hline Time in 1:1 Setting ${ }^{a}$ & $36(18.8-62.5)$ & $19(10-40)$ \\
\hline Time in 1:2 Setting ${ }^{a}$ & $5(3-11)$ & $4(2-14)$ \\
\hline Time in 1:3 Setting ${ }^{a}$ & $2(1-3)$ & 1 \\
\hline PTT goal range $60-80$ & $54(65.9)$ & N/A \\
\hline PTT goal range $50-70$ & $21(25.6)$ & N/A \\
\hline Other PTT goal & $7(8.5)$ & N/A \\
\hline Rate of heparin (units $/ \mathrm{kg} / \mathrm{hr})^{\mathrm{a}}$ & $12(9-15)$ & N/A \\
\hline Time on heparin (hours) ${ }^{a}$ & $56(32-89$ & N/A \\
\hline Percent of time in therapeutic range $\mathrm{e}^{\mathrm{a}}$ & $44.8 \pm 27.8$ & N/A \\
\hline $\begin{array}{l}\text { Received concomitant aspirin } \\
\text { monotherapy }\end{array}$ & $42(51.2)$ & $42(64.6)$ \\
\hline $\begin{array}{l}\text { Received concomitant dual } \\
\text { antiplatelet therapyc }\end{array}$ & $22(26.8)$ & $9(13.8)$ \\
\hline $\begin{array}{l}\text { Received concomitant dual } \\
\text { antiplatelet therapy with clopidogrel } \\
\text { and aspirin }\end{array}$ & $14(17.1)$ & $9(13.8)$ \\
\hline $\begin{array}{l}\text { Received concomitant dual } \\
\text { antiplatelet therapy with ticagrelor } \\
\text { and aspirin }\end{array}$ & $8(9.8)$ & 0 \\
\hline
\end{tabular}

All values are $\mathrm{n}(\%)$ unless otherwise specified

$P T T$ partial thromboplastin time

${ }^{a}$ mean $+/-S D$

${ }^{\mathrm{b}}$ median (IQR)

${ }^{\mathrm{C}}$ Dual antiplatelet therapy is defined as being on both aspirin and a

$\mathrm{P} 2 \mathrm{Y}_{12}$ inhibitor

regression was performed for bleeding and thromboembolic events there were no significant differences found in the major composite outcomes (Table 4). There were no differences found in minor endpoints of hospital length of stay, intensive care unit length of stay, in- hospital morality, major outcome events happening within $24 \mathrm{~h}$, or major outcome events occurring within $48 \mathrm{~h}$ of insertion (Table 5 ).

In the subgroup analysis of patients on outpatient anticoagulation prior to hospitalization, a total of 43 and 45 patients were included in the heparin and nonheparin groups, respectively. The bleeding endpoint occurred in 25.6 and $20 \%$ in the heparin and non-heparin groups, respectively $(p=0.40)$. The thrombotic endpoint occurred in 4.7 and $6.7 \%$ in the heparin and non-heparin groups, respectively $(p=1)$ (Table 6$)$. There were no differences found in minor endpoints between groups (Table 7).

\section{Discussion}

In our retrospective analysis assessing the safety and efficacy of anticoagulation in patients on IABPs, we found no differences in major outcomes of bleeding or thrombotic events. These findings are similar to those of several other small studies comparing anticoagulation strategies in patients on an IABP [5-7].

Jiang et al. compared patients on an IABP with UFH versus those receiving no heparin in a single center, randomized trial. This study consisted of 153 patients who received either heparin with a goal aPTT of 50-70, or no anticoagulation while on an IABP. Patients in the heparin versus non-heparin group were matched based on demographics and comorbidities. As with our patients, they found no statistical differences in limb ischemia or IABP thrombus. Their study, however, did find statistically higher rates of bleeding in the heparin group as compared to the non-heparin group [6]. All patients in this group received either percutaneous coronary intervention or coronary artery bypass grafting, while our study included a more diverse patient population

Table 4 Safety and Efficacy Outcomes

\begin{tabular}{|c|c|c|c|c|c|}
\hline & $\begin{array}{l}\text { Heparin group } \\
(n=82)\end{array}$ & $\begin{array}{l}\text { Non-heparin group } \\
(n=65)\end{array}$ & $\begin{array}{l}\text { Unadjusted } \\
p \text { value }\end{array}$ & $\begin{array}{l}\text { Adjusted* odds } \\
\text { ratio }\left(95 \% \mathrm{Cl}^{\mathrm{a}}\right)\end{array}$ & $\begin{array}{l}\text { Adjusted }{ }^{*} p \\
\text { value }\end{array}$ \\
\hline Main bleeding endpoint & $17(20.7)$ & $13(20.0)$ & 0.91 & $0.80(0.31-2.09)$ & 0.65 \\
\hline Major access site bleeding & $2(2.4)$ & $3(4.6)$ & 0.47 & & \\
\hline Minor access site bleeding & $4(4.9)$ & $5(7.7)$ & 0.51 & & \\
\hline Major non-access site bleeding & $3(3.7)$ & $3(4.7)$ & 1 & & \\
\hline Minor non-access site bleeding & $7(8.5)$ & $1(1.5)$ & 0.08 & & \\
\hline Main thrombotic endpoint & $6(7.3)$ & $5(7.7)$ & 1 & $1.62(0.42-6.3)$ & 0.42 \\
\hline Limb ischemia & $3(3.7)$ & $1(1.5)$ & 0.63 & & \\
\hline Device thrombosis & $1(1.2)$ & 0 & $\mathrm{~N} / \mathrm{A}$ & & \\
\hline Venous thromboembolism & $1(1.2)$ & $2(3.1)$ & 0.58 & & \\
\hline Ischemic stroke & $1(1.2)$ & $2(3.1)$ & 0.58 & & \\
\hline
\end{tabular}

All values are $\mathrm{n}(\%)$

${ }^{a}$ confidence interval

*A post hoc multivariate logistic regression was performed for major composite endpoints adjusting for sex, creatinine clearance, use of dual antiplatelet therapy, and patient's location (coronary care unit versus cardiac surgery unit) 
Table 5 Minor Outcomes

\begin{tabular}{llll}
\hline & Heparin group $(\boldsymbol{n}=\mathbf{8 2})$ & Non-heparin group $(\boldsymbol{n}=\mathbf{6 5})$ & $\boldsymbol{p}$ value \\
\hline Hospital length of stay $^{\mathrm{a}}$ & $12(7-23)$ & $13.5(9-21)$ & $5(3-8)$ \\
Intensive care unit length of stay $^{\mathrm{a}}$ & $5(3-10)$ & $16(24.6)$ & 0.47 \\
In-hospital mortality & $18(22.0)$ & $7(10.7)$ & 0.70 \\
Bleeding and thrombotic events occurring within 24h of placing IABP & $11(13.4)$ & $3(4.7)$ & 1 \\
Bleeding and thrombotic events occurring within 48 h of placing IABP & $3(3.7)$ & 0.24 \\
\hline
\end{tabular}

All values are $n(\%)$ unless otherwise specified

amedian (IQR)

with any indication for an IABP, excluding endarterectomy.. Our study also looked at patients with different PTT goals, therefore providing additional information while in this study all heparinized patients had a PTT goal of 50-70.

Cooper et al. compared a selective heparin group $(n=102)$ versus a universally heparin group $(n=150)$ in a single center, prospective, cohort study. This study evaluated patients that had been admitted to the CCU. In the selective group, only patients with an indication for anticoagulation other than IABP received heparin. Similar to our analysis, this study found no statistical differences in limb ischemia, major IABP-related complications, or access site bleeding, though there was a statistically significant increase in overall bleeding events in the universal heparin group as compared to the selective heparin group. They also found no difference in $\mathrm{CCU}$ length of stay, total hospital length of stay, or mortality. Of the patients in the selective heparin group, $53 \%$ received heparin as compared to our analysis in which our control group received no anticoagulation [7].

Chin et al. retrospectively assessed 18,875 patients who received an IABP from 1996 to 2004 using data from the Benchmark Counterpulsation Outcomes Registry. This large observational study compared outcomes between patients who received anticoagulation as compared to those who did not receive anticoagulation. Overall, they found those who received anticoagulation had fewer in-hospital deaths and less limb ischemia without an increase in bleeding events. The authors concluded that anticoagulation should be used whenever possible for all IABP patients. This study differs from our findings and the findings of several retrospective studies demonstrating no difference in thrombotic outcomes when comparing anticoagulation strategies. Although this is a large study, it is difficult to draw any strong conclusions given the retrospective, observational nature of the study [9].

In patients on heparin who experienced any bleeding event, 8 had a PTT goal lower than $60-80 \mathrm{~s}$. A lower PTT goal was likely targeted in these patients due to an increased bleeding risk at baseline. The last documented PTT was supratherapeutic in 6 patients with a major bleed. As previously mentioned, the heparin group had more patients on DAPT compared to the non-heparin group. This is most likely due to more patients in the heparin group presented with acute coronary syndrome events. Of those who had a bleeding event, 6 (37.5\%) were receiving concomitant DAPT in the heparin group, and $2(16.7 \%)$ were on concomitant DAPT in the nonheparin group. Although DAPT has been proven to increase bleed risk, especially in combination with anticoagulation, there was still no difference in bleeding

Table 6 Subgroup Analysis Major Outcomes

\begin{tabular}{llll}
\hline & Heparin group $(\boldsymbol{n}=\mathbf{4 3})$ & Non-heparin group $(\boldsymbol{n}=\mathbf{4 5})$ & $\boldsymbol{p}$ value \\
\hline Composite endpoint of bleeding & $11(25.6)$ & $8(17.8)$ & 0.44 \\
Major access site bleeding & $1(2.3)$ & $2(4.4)$ & 1 \\
Minor access site bleeding & $3(6.9)$ & $2(4.4)$ & $3(6.7)$ \\
Major non-access site bleeding & $2(4.7)$ & $1(2.3)$ & 1 \\
Minor non-access site bleeding & $5(11.6)$ & $3(6.7)$ & 1 \\
Composite endpoint of thrombosis events & $2(4.7)$ & $1(2.2)$ & 1 \\
Limb ischemia & $1(2.3)$ & 0 & 1 \\
Device thrombosis & 0 & $1(2.2)$ & 1 \\
VTE & $1(2.3)$ & $1(2.2)$ & 1 \\
Ischemic stroke & 0 & & 1 \\
\hline
\end{tabular}

All values are $n(\%)$ 
Table 7 Subgroup Analysis Minor Outcomes

\begin{tabular}{llll}
\hline & Heparin group $(\boldsymbol{n}=\mathbf{4 3})$ & Non-heparin group $(\boldsymbol{n}=\mathbf{4 5})$ & $\boldsymbol{p}$ value \\
\hline Hospital LOS & $11(6-16)^{\mathrm{a}}$ & $12.5(9-20)^{\mathrm{a}}$ & 0.15 \\
ICU LOS & $5(2.5-6)^{\mathrm{a}}$ & $6(3-7.5)^{\mathrm{a}}$ & 0.91 \\
In-hospital & $9(21)$ & $8(17.8)$ & 0.71 \\
Bleeding and thrombotic events occurring within 24h of placing IABP & $4(9.3)$ & $5(11.1)$ & 1 \\
Bleeding and thrombotic events occurring within 48 h of placing IABP & $3(6.9)$ & $2(4.4)$ & 1 \\
\hline
\end{tabular}

All values are $n(\%)$ unless otherwise specified

${ }^{a}$ median (IQR)

shown in our study in our post hoc multivariate analysis adjusting for DAPT $[10,11]$.

There were several limitations to this study. The majority of patients in the heparin group were medical patients admitted to the CCU, while the majority of non-heparinized patients were surgical patients admitted to the CSICU. Cardiac surgery patients may have a higher baseline risk of bleeding post operatively than medical patients despite use of anticoagulation. Rates of reoperation due to bleeding can be up to $8 \%$ post CABG, and there were significantly more patients in the nonheparin group who received CABG [12]. Of the patients who experienced a bleed, $5(32.2 \%)$ patients in the heparin group were cardiac surgery patients and 8 (66.7\%) patients in the non-heparin group were cardiac surgery patients. Despite these potential differences in patient populations, there was no difference found in hospital length of stay, ICU length of stay, or mortality between the two groups. It is also important to note that the heparin group may have been more susceptible to IABP related adverse events given that they were on an IABP for longer. Our subgroup analysis also has limitations. We attempted to examine a patient population with no other indication for anticoagulation by excluding patients who had an outpatient prescription for an anticoagulant prior to admission. If there was no documentation of an outpatient prescription, or if the patient had a new event requiring anticoagulation (i.e. new onset atrial fibrillation during indexed hospitalization), they were not excluded from this subgroup analysis. Another limitation of this study is that it does not explore patients who were on anticoagulants other than heparin (i.e. bivalirudin). We excluded these patients in order to directly compare heparin to no anticoagulation, as heparin is the preferred agent at our institution due to factors such as ability to reverse, lack of renal clearance, and cost. Patients were also excluded if they underwent an endarterectomy procedure, as there is a very specific, fixed rate of heparin utilized by our CSICU service based on chest tube output.

There are no large, prospective, randomized, controlled trials comparing anticoagulation strategies in IABPs. Although this is a small, single center study, our study would be the first to compare anticoagulation versus non-anticoagulation in patients on an IABP within the past 10 years.

Overall, our study had similar rates of bleeding and thrombotic events when compared to other literature surrounding IABP use [2, 3, 5-8]. Although we did not find a statistically significant difference in bleeding, there were numerically more reported bleeding events in the heparin group as compared to the non-heparin group.

\section{Conclusion}

There were no significant differences found in major endpoints of bleeding and thrombotic events in patients who received anticoagulation while on an IABP versus those who did not receive anticoagulation. Further evaluation of the benefit of anticoagulation in IABPs needs to be explored in larger, prospective trials.

\section{Acknowledgements}

Not applicable.

\section{Authors' contributions}

The author(s) read and approved the final manuscript.

\section{Funding}

This research did not receive any specific grant from funding agencies in the public, commercial, or not-for-profit sectors.

Availability of data and materials

Not applicable.

\section{Declarations}

Ethics approval and consent to participate

Not applicable.

Consent for publication

Not applicable.

\section{Competing interests}

Not applicable.

Received: 17 August 2020 Accepted: 7 June 2021

Published online: 29 June 2021

\section{References}

1. Lefemine AA, Kosowsky B, Madoff I, Black H, Lewis M. Results and complications of intra-aortic balloon pumping in surgical and medical patients. Am J Cardiol. 1977;40(3):416-20. https://doi.org/10.1016/0002-914 9(77)90165-5. 
2. Sjauw KD, Engstrom AE, Vis MM, van der Schaaf RJ, Baan J Jr., Koch KT, de winter RJ, Piek JJ, Tijssen JG, Henriques JP. A systematic review and metaanalysis of intra-aortic balloon pump therapy in ST-elevation myocardial infarction: should we change the guidelines? Eur Heart J 2009;30:459-68.

3. Stone GW, Ohman EM, Miller MF, Joseph DL, Christenson JT, Cohen M, et al. Contemporary utilization and outcomes of intra-aortic balloon counterpulsation in acute myocardial infarction: the benchmark registry. J Am Coll Cardiol. 2003;41(11):1940-5. https://doi.org/10.1016/50735-1097(03 )00400-5.

4. Rihal CS, Naidu SS, Givertz MM, Szeto WY, Burke JA, Kapur NK, et al. 2015 SCAI/ACC/HFSA/STS clinical expert consensus statement on the use of percutaneous mechanical circulatory support devices in cardiovascular care. J Card Fail. 2015;21(6):499-518. https://doi.org/10.1016/..cardfail.2015.03.002.

5. Lazar HL, Bao Y, Rivers S, Treanor PR, Shemin RJ. Decreased incidence of arterial thrombosis using heparin-bonded intraaortic balloons. Ann Thorac Surg. 1999;67(2):446-9. https://doi.org/10.1016/S0003-4975(98)01139-4.

6. Jiang $C Y$, Zhao $L L$, Wang JA, Mohammod B. Anticoagulation therapy in intra-aortic balloon counterpulsation: does IABP really need anticoagulation? J Zhejiang Univ Sci. 2003:4(5):607-11. https://doi.org/10.1631/ jzus.2003.0607.

7. Cooper HA, Thompson E, Panza JA. The role of heparin anticoagulation during intra-aortic balloon counterpulsation in the coronary care unit. Acute Card Care. 2008;10(4):214-20. https://doi.org/10.1080/17482940802483048.

8. Schulman S, Kearon C. Subcommittee on control of anticoagulation of the scientific and standardization Committee of the International Society on thrombosis and Haemostasis. Definition of major bleeding in clinical investigations of antihemostatic medicinal products in non-surgical patients. J Thromb Haemost. 2005;3(4):692-4. https://doi.org/10.1111/j.1538-7836.2 005.01204.X

9. Chin CT, Kelly R, et al. The Impact of Anticoagulation During Intra-Aortic Balloon Counterpulsation Pump Placement on In-Hospital Outcomes in 18,875 Patients Undergoing Cardiac Revascularization. Circulation. 2010;122: A10175.

10. Dewilde WJ, Oirbans T, Verheugt FW, et al. Use of clopidogrel with or without aspirin in patients taking oral anticoagulant therapy and undergoing percutaneous coronary intervention: an open-label, randomised, controlled trial. Lancet. 2013;381(9872):1107-15. https://doi. org/10.1016/50140-6736(12)62177-1.

11. Tompkins C, Cheng A, Dalal D, Brinker JA, Leng CT, Marine JE, et al. Dual antiplatelet therapy and heparin "bridging" significantly increase the risk of bleeding complications after pacemaker or implantable cardioverterdefibrillator device implantation. J Am Coll Cardiol. 2010;55(21):2376-82. https://doi.org/10.1016/j.jacc.2009.12.056.

12. Mehta RH, Sheng S, O'Brien SM, Grover FL, Gammie JS, Ferguson TB, et al. Reoperation for bleeding in patients undergoing coronary artery bypass surgery: incidence, risk factors, time trends, and outcomes. Circ Cardiovasc Qual Outcomes. 2009;2(6):583-90. https://doi.org/10.1161/CIRCOUTCOMES.1 09.858811 .

\section{Publisher's Note}

Springer Nature remains neutral with regard to jurisdictional claims in published maps and institutional affiliations.

Ready to submit your research? Choose BMC and benefit from:
- fast, convenient online submission
- thorough peer review by experienced researchers in your field
- rapid publication on acceptance
- support for research data, including large and complex data types
- gold Open Access which fosters wider collaboration and increased citations
- maximum visibility for your research: over 100M website views per year
At BMC, research is always in progress.
Learn more biomedcentral.com/submissions

